Relations industrielles

Industrial Relations

\title{
Brève histoire du syndicalisme ouvrier au Canada, Ls-Laurent Hardy, Coll. " Les voix ». Les Editions de l'Hexagone, Montréal 1958, 155 pp.
}

\section{Gérard Dion}

Volume 14, numéro 2, avril 1959

URI : https://id.erudit.org/iderudit/1022325ar

DOI : https://doi.org/10.7202/1022325ar

Aller au sommaire du numéro

Éditeur(s)

Département des relations industrielles de l’Université Laval

ISSN

0034-379X (imprimé)

1703-8138 (numérique)

Découvrir la revue

Citer ce compte rendu

Dion, G. (1959). Compte rendu de [Brève histoire du syndicalisme ouvrier au Canada, Ls-Laurent Hardy, Coll. « Les voix ». Les Editions de l'Hexagone, Montréal 1958, 155 pp.] Relations industrielles / Industrial Relations, 14(2), 303-303. https://doi.org/10.7202/1022325ar

Tous droits réservés (C Département des relations industrielles de l’Université Laval, 1959
Ce document est protégé par la loi sur le droit d'auteur. L'utilisation des services d'Érudit (y compris la reproduction) est assujettie à sa politique d'utilisation que vous pouvez consulter en ligne.

https://apropos.erudit.org/fr/usagers/politique-dutilisation/ 
ce prognostics of suocess or failure in solving a crisis situation have at all times been particularly hazardous because of the contradiotions and surprising reversals of public and private attitudes."

\section{GÉrard Dion}

Brève histoire du syndicalisme ouvrier au Canada, Ls-Laurent Hardy, Coll. \& Les voix ». Les Editions de l'Hexagone, Montréal 1958, 155 pp.

Les ouvrages en langue française sur le syndicalisme ouvrier au Canada sont rares. En dehors des essais de Charpentier sur le syndicalisme catholique, du volume de J.-P. Després \& Le mouvement ouvrier canadien » publié par notre département chez Fides en 1947, on ne trouve que des brochures, des articles de revues, (particulièrement dans Relations Industrielles) qui envisagent l'un ou l'autre aspect de cette question. Le titre du volume de M. Hardy est exact. C'est une brève synthèse que présente l'auteur. Il s'est servi des études déjà publiées en langue anglaise et a eu accès aux archives de la CTCC. Son mérite n'est pas tant l'originalité ni l'analyse des causes ou circonstances qui ont influencé l'évolution du syndicalisme, que d'être une synthèse qui embrasse tous les événements jusqu'à aujourd'hui. L'auteur, avec raison, s'étend beaucoup plus longuement sur la CTCC que les autres centrales. Il comble ainsi une lacune que l'on pouvait déplorer chez Logan, "Trade Union in Canada" (MacMillan, 1948) et même, à un degré moindre cependant, chez Jamieson, "Industrial Relations in Canada" (MacMillan, 1957). Une véritable histoire du syndicalisme au Canada - et surtout dans la province de Québec, - reste à faire. Cependant nous croyons que M. Hardy a rendu à tous un grand service en publiant cette synthèse. Même les syndiqués y apprendront quelque chose.

\section{GÉRARD Dion}

The Appraisal Interview. By N.R.F. Maier, New York: John Wiley \& Sons, 1958, 246 pp.

Ce volume a pour but d'étudier la relation de cause à effet qui existe dans une situation d'entrevue dont le but est d'évaluer la performance de l'employé.
Depuis de nombreuses années Maier s'est voué à la recherche dans le domaine des relations humaines. Il s'est surtout manifesté dans le développement et l'entraînement du personnel de la gérance. Il a constaté que l'entrevue d'évaluation (appraisal interview) est utilisée pour développer le personnel administratif, mais que les résultats obtenus sont superficiels ou nuls. Pourquoi? Parce qu'en général on a voulu trop accomplir avec cette méthode et que ce faisant on n'arrivait à aucun résultat pratique. Plusieurs objectifs que l'on tentait d'atteindre d'un seul coup se sont montrés incompatibles. Placé dans une situation confuse, l'employé considérait l'évaluation comme injuste et arbitraire.

Maier démontre qu'en étudiant les objectifs à atteindre on peut utiliser trois méthodes. Chacune d'elles est caractérisée par une entrevue qui demande une technique d'approche bien spécifique. Voici un résumé de chaque entrevue.

\section{1-L'entrevue d'évaluation directive: \\ (Tell and Sell Method)}

L'objectif initial de cette méthode est de communiquer objectivement à l'employé les résultats de l'évaluation. De plus, le patron doit faire accepter cette évaluation par l'employé et l'amener à suivre un programme d'amélioration prédéterminé. Parce qu'elle est simple, cette méthode est la plus utilisée. Heureusement Maier a tôt fait de démontrer qu'elle est inefficace ot même dangereuse pour la raison suivante: elle assume que l'employé acceptera tout et changera son comportement.

Toutefois si l'employé refuse l'évaluation, le patron devient agressif. La situation détériore rapidement soit en un conflit soit en une soumission passive de la part du subalterne. Incidemment les gains abtenus sont insignifiants comparativement aux pertes: perte d'intérêt pour le travail, relations tendues entre patron et employé. L'employé apprend à faire ce qui plaît au patron. Cette approche autoritaire et dominatrice, qui empêche l'employé d'exposer son point de vue, tue toute initiative et toute créativité. Ce sont les considérations émotives et subjectives qui dominent dans l'entrevue d'évaluation directive. 